\title{
Verification and Assessment on the Aviation Pouring Organic Glass's Comprehensive Performance under Different Environment Conditions
}

\author{
Xin-Kun WANG ${ }^{1,2, a .{ }^{*}}$, Shi-Cheng WEI ${ }^{3}$, Bin-Shi $X U^{3}$, Xu YAN ${ }^{2}$, Hong-Hua XIA ${ }^{2}$ \\ ${ }^{1}$ Materials science \& Engineering school of Beihang University, Beijing, China \\ ${ }^{2}$ Beijing Aeronautical Technology Research Center, Beijing, China \\ ${ }^{3}$ Key Laboratory of Remanufacturing of the Academy of Armored Forces Engineering, Beijing, China \\ ${ }^{a} E-m a i l: w a n g x i n k u n 1010 @ 163 . c o m$
}

Keywords: Pouring organic glass; YB-3; Tensile Properties; Bending Properties; Stress-solvent Silver Grain; Impact properties; Accelerated aging

\begin{abstract}
The performance variations of pouring organic glass under the different accelerated aging test conditions whose brand is YB- 3 have been studied, which have reached the specified life, the result show that the overall trends the properties of the YB- 3 being used the specified life slightly decrease following the experiment time increasing, which include tensile property, bending property, stress-solvent(95\% ethyl alcohol). When the samples have been respectively experienced 360h damp heat test, $720 \mathrm{~h}$ heat aging test, $720 \mathrm{~h}$ salt fog test, bending strength are respectively $143.2 \mathrm{MPa}$, $130.5 \mathrm{MPa}, 141.6 \mathrm{MPa}$ and the bending strength retention rate are higher 90 percent, tensile strength are respectively $68.1 \mathrm{MPa}, 69.7 \mathrm{MPa}, 68.3 \mathrm{MPa}$ and the bending strength retention rate are higher 92 percent, stress-solvent silver grain(95\% enthyl alcohol) are respectively $18.8 \mathrm{MPa}, 20.8 \mathrm{MPa}$, 16.9MPa., which are no less than this type material's indicator. Although the YB-3 has reached the specified life, the performance only slightly decline and has the potential to continue to use a certain calendar time.
\end{abstract}

\section{Introduction}

Pouring organic glass is made by bulk polymerization method and the main raw material is methyl methacrylate monomers, as a kind of typical thermoplastic plastics, it has very high light transmittance, good mechanical properties, the molding process is simple, and it can be easily made different shape, so it is wide used to make cockpit transparent parts, such as training plane, strike aircraft whose mach number are relative low[1, 2]. YB-3 is one this kind material typical representative, and meet the requirements to the cockpit transparent parts when the aircraft's mach number is no greater than 1.8[3]. If the connection methods of the cockpit transparent parts are different, including hard connection, soft connection and hybrid connection, the lives of the transparent parts are different. In this paper, the connection method of the cockpit transparent parts adapts soft connection, its calendar life is 6 years, fatigue life is 1000 hours, as the calendar time reaches 6 years or the flight time gets to 1000 hours, cockpit transparent parts will have to be replaced even though the technical status is good. It will be cost hundreds of thousands RMB and a lot of manpower, material resources and property be wasted. In this paper, the performance variations of the aircraft cockpit transparent parts whose brand is YB-3 have been studied under different accelerated aging environments, which have been reached the specified life, including tensile properties, bending properties, stress-solvent silver grain ,impact properties as well as the sample fracture morphology and mechanical behavior curve, the results will provide the technical support to prolong this type cockpit transparent parts life, having significant economic and military value[4, 5]. 


\section{Materials and Methods}

\section{Materials}

Samples are made from the cockpit transparent parts that have been used to the specified life, the service calendar time is 8 years and 10 months, the flight time gets to 1186 hours and 48 minutes.

\section{Sample Processing}

According to GB/T 1043 (Plastics-Determination of charpy impact strength of rigid materials), GB/T 9341 (Plastics-Determination of flexural properties), GB/T 1040 (Plastics-Determination of tensile properties), HB 6657 (Aviation organic glass silver grain test method), manufacture the including bending, tensile, impact and stress- solvent silver grain samples.

\section{Test Content and Test Conditions}

(1)Damp heat test

According to GJB150.9A (Laboratory environmental test methods for military material-Part 9: Damp heat test), carry out damp heat test, test temperature is $(45 \pm 2)^{\circ} \mathrm{C}$, relative humidity is (95 \pm 5$) \%$,experimental time is respectively $120 \mathrm{~h}, 360 \mathrm{~h}, 720 \mathrm{~h}$, test performance variations of the samples, fracture morphology and mechanical behavior curve.

(2)Heat aging test

According to GB/T7141 (Plastics-Methods of heat aging), carry out heat aging test, test temperature is $(100 \pm 2){ }^{\circ} \mathrm{C}$, experimental time is respectively $120 \mathrm{~h}, 360 \mathrm{~h}$, $720 \mathrm{~h}$, test performance variations of the samples, fracture morphology and mechanical behavior curve.

(3)Salt fog test

According to GJB150.11A (standard Laboratory environmental test methods for military material-Part 11: Salt fog test), carry out salt fog test, test temperature is $(50 \pm 2)^{\circ} \mathrm{C}, \mathrm{NaCl}$ concentration is 5 percent, salt fog settlement is $(1-2) \mathrm{ml} /\left(\mathrm{h} \cdot 80 \mathrm{~cm}^{2}\right)$, experimental time is respectively $120 \mathrm{~h}, 360 \mathrm{~h}, 720 \mathrm{~h}$, test performance variations of the samples, fracture morphology and mechanical behavior curve.

\section{Experimental Data Processing}

(1)Impact test

According to formula (1), deal with the impact test data

$$
\text { Eq.1 a }=\frac{\mathrm{A}}{\mathrm{b} \cdot \mathrm{d}_{\mathrm{k}}} \times 10^{3}
$$

In formula, A is absorbing impact energy, $b$ is the sample's breadth, $\mathrm{d}_{\mathrm{k}}$ is the sample's thickness. (2)Bending test

According to formula (2), deal with the bending test data

$$
\text { Eq.2 } \sigma_{\mathrm{f}}=\frac{3 \mathrm{~F} \cdot \mathrm{L}}{2 b \cdot h^{3}}
$$

In formula, $\sigma_{\mathrm{f}}$ is bending stress, $\mathrm{F}$ is the applied stress to the sample, $\mathrm{L}$ is span, $\mathrm{b}$ is the sample's breadth, $h$ is the sample's thickness.

(3) Tensile test

According to formula (3), deal with the tensile test data

$$
\text { Eq.3 } \sigma_{\mathrm{t}}=\frac{\mathrm{P}}{b \cdot d}
$$

In formula, $\sigma_{t}$ is tensile strength, $P$ is maximum load, $b$ is the sample's breadth, $d$ is the sample's thickness.

(4)Stress-solvent silver grain 
According to formula (4), deal with the stress-solvent silver grain data

$$
\mathrm{Eq} .4 Y=\frac{3 \mathrm{P} \cdot \mathrm{a}}{b \cdot h^{2}}
$$

In formula, $\mathrm{P}$ is the threshold stress value when the silver grain produces, $\mathrm{a}$ is the spacing between fulcrum, $\mathrm{b}$ is the sample's breadth, $\mathrm{h}$ is the sample's thickness

\section{Results and Analysis}

\section{Bending Test Results}

According to GB/T9341 (Plastics-Determination of flexural properties), test the sample's flexural properties after they have been experienced different time accelerated aging test, including damp heat test, heat aging test, salt fog test, stress-solvent silver grain test, loading speed is $2 \mathrm{~mm} / \mathrm{min}$, the results are shown in Table 1.

Table 1 Results of Bending Performance

\begin{tabular}{cccccccc}
\hline Test stage & time & $\mathrm{b} /(\mathrm{mm})$ & $\mathrm{h} /(\mathrm{mm})$ & $\mathrm{L} /(\mathrm{mm})$ & $\mathrm{F} /(\mathrm{N})$ & $\sigma \mathrm{f} /(\mathrm{MPa})$ & $\begin{array}{c}\text { Strength retention } \\
\text { rate/(\%) }\end{array}$ \\
\hline $\begin{array}{c}\text { Initial } \\
\text { sample }\end{array}$ & $0 \mathrm{~h}$ & 10.3 & 4.1 & 60 & 301.88 & 156.9 & - \\
\hline \multirow{2}{*}{$\begin{array}{c}\text { Damp heat } \\
\text { test }\end{array}$} & 360h & 10.4 & 4.3 & 60 & 316.72 & 151.1 & 96.3 \\
& $720 \mathrm{~h}$ & 10.4 & 4.1 & 60 & 244.8 & 126.0 & 91.3 \\
\hline \multirow{2}{*}{ Heat aging } & $120 \mathrm{~h}$ & 10.1 & 4.5 & 60 & 329.6 & 145.0 & 90.3 \\
test & $360 \mathrm{~h}$ & 10.4 & 4.1 & 60 & 253.4 & 130.5 & 83.2 \\
\hline \multirow{2}{*}{ Salt fog } & $720 \mathrm{~h}$ & 10.1 & 4.2 & 60 & 219.28 & 110.8 & 70.6 \\
test & $360 \mathrm{~h}$ & 10.4 & 4.3 & 60 & 317.84 & 148.8 & 94.8 \\
\hline
\end{tabular}

From Table 1, we can see, after experiencing 120 hours damp heat test, 120 hours heat aging test, 120 hours salt fog test, the sample bending strength are respectively 151.1MPa, 145.0MPa, 148.8MPa, compared with that of the initial sample, strength retention rate are higher 92 percent, after experiencing 360 hours accelerated aging test, they are respectively $143.2 \mathrm{MPa}, 130.5 \mathrm{MPa}$, $141.6 \mathrm{MPa}$ and the bending strength retention rate are higher 90 percent, after experiencing 720 hours accelerated aging test, they are respectively $126.0 \mathrm{MPa}, 110.8 \mathrm{MPa}, 116.1 \mathrm{MPa}$ and the bending strength retention rate are higher 70 percent. The results show when the samples which have been used to the specified life experience 360h heat aging test, 360 hours heat aging test, 360 hours salt fog test, the bending strength only slightly decline, so this type casting organic glass have the potential to continue to use a certain calendar time.

\section{Tensile Test results}

\section{Tensile Strength}

According to GB/T1040 (Plastics-Determination of tensile properties), test the sample's tensile properties after they have been experienced different time accelerated aging test, including damp heat test, heat aging test, salt fog test, Stress-solvent silver grain test, loading speed is $2 \mathrm{~mm} / \mathrm{min}$, the results are shown in Table 2. 
Table 2 Results of Tensile Properties

\begin{tabular}{ccccccc}
\hline Test stage & time & $\mathrm{b} /(\mathrm{mm})$ & $\mathrm{d} /(\mathrm{mm})$ & $\mathrm{P} /(\mathrm{N})$ & $\sigma \mathrm{t} /(\mathrm{MPa})$ & $\begin{array}{c}\text { Strength retention } \\
\text { rate/(\%) }\end{array}$ \\
\hline Initial & $0 \mathrm{~h}$ & 10.2 & 8.1 & 5973.84 & 73.3 & - \\
sample & & & & & & 94.7 \\
Damp heat & $120 \mathrm{~h}$ & 19.9 & 8.2 & 11323.92 & 69.4 & 94.5 \\
test & $360 \mathrm{~h}$ & 20.0 & 8.1 & 11231.44 & 69.3 & 92.9 \\
\hline \multirow{2}{*}{ Heat aging } & $720 \mathrm{~h}$ & 10.3 & 8.1 & 5679.92 & 68.1 & 99.9 \\
test & $120 \mathrm{~h}$ & 10.3 & 8.1 & 6101.16 & 73.2 & 95.5 \\
& $760 \mathrm{~h}$ & 10.4 & 8.1 & 5896.68 & 70 & 95.1 \\
\multirow{2}{*}{ Salt fog test } & $120 \mathrm{~h}$ & 10.4 & 8.1 & 5870.36 & 69.7 & 97.3 \\
& $360 \mathrm{~h}$ & 20.0 & 8.1 & 11540.16 & 71.3 & 96.7 \\
\hline
\end{tabular}

From Table 2, we can see, after experiencing 120 hours damp heat test, 120 hours heat aging test, 120 hours salt fog test, the sample tensile strength are respectively 69.4MPa, 73.2MPa, 71.3MPa, compared with that of the initial sample, tensile strength retention rate are higher 94 percent, after experiencing 360 hours accelerated aging test, they are respectively 69.3MPa, 70.0MPa, 70.9MPa and the bending strength retention rate are higher 94 percent, after experiencing 720 hours accelerated aging test, they are respectively 68.1MPa, 69.7MPa, 68.3MPa and the bending strength retention rate are higher 92 percent. The results show when the samples which have been used to the specified life experience $720 \mathrm{~h}$ heat aging test, 720 hours heat aging test, 720 hours salt fog test, the tensile strength only slightly decline, so this type casting organic glass have the potential to continue to use a certain calendar time. The tensile strength-deformation curves after experiencing accelerated aging test are shown in Fig 1.
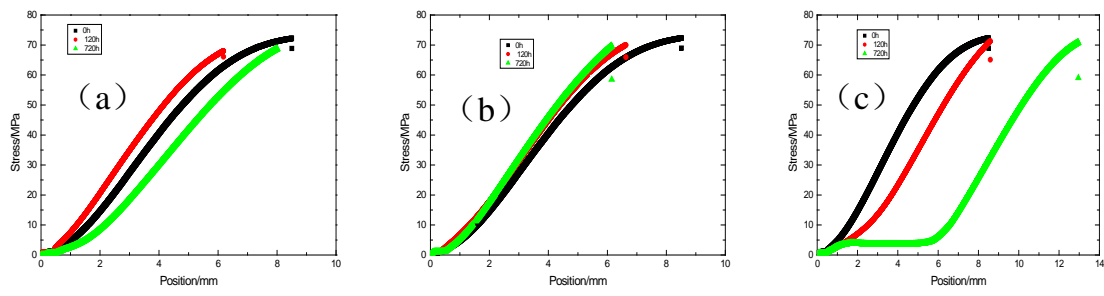

Fig.1 Tensile strength-deformation curve after experiencing accelerated aging test (a) after damp heat test, (b) after heat aging test, (c) after salt fog test

\section{Tensile Fracture Morphology}

Figs 2-5 are respectively the sample tensile fracture morphology of initial YB-3 sample being used to the specified life, of that experiencing 720 hours damp heat test, of that experiencing 720 hours heat aging test and of that experiencing 720 hours salt fog test. From Figs 2-5, we can see that the 4 kinds different sample tensile fracture morphologies have the similar characteristics, the whole fracture can divide 3 areas: source area, near source area, far away from source area. Fracture surfaces are relatively smooth, present fast fracture characteristics, the source area take on punctuate character, but there are difference among the 4 samples' extension area, it takes on parabolic characteristics on the initial sample fracture, they take on toughness characteristics on the sample fracture after experiencing 720 hours damp heat test and experiencing 720 hours salt fog test, it takes on rivers shape pattern on the sample fracture after experiencing 720 hours heat aging test. 

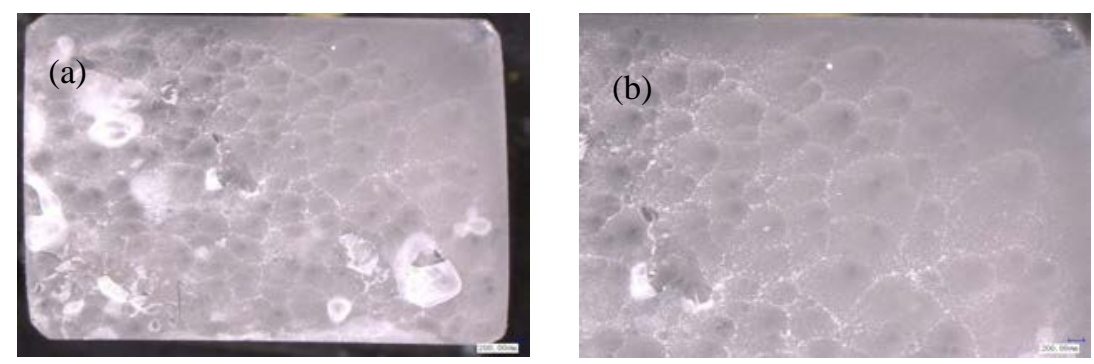

Fig.2 Tensile morphology before Accelerated aging test, (a)fracture picture, (b)source area morphology
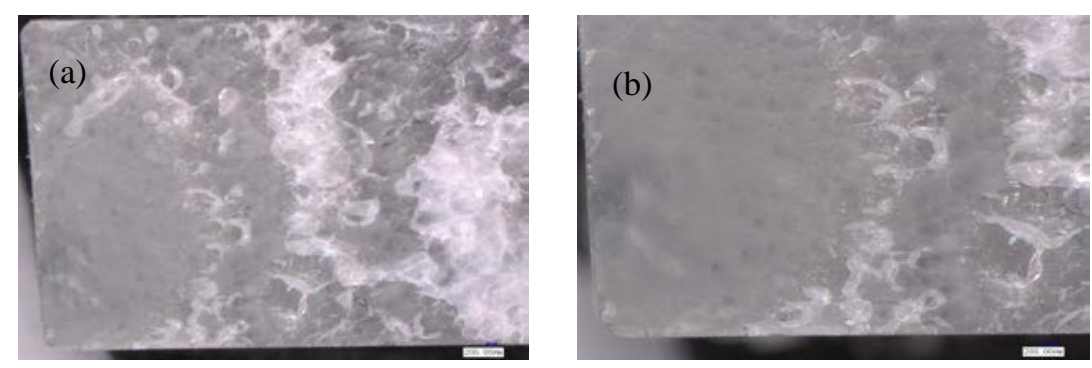

Fig.3 Tensile morphology experiencing 720 hours damp heat test, (a)fracture picture, (b)source area morphology
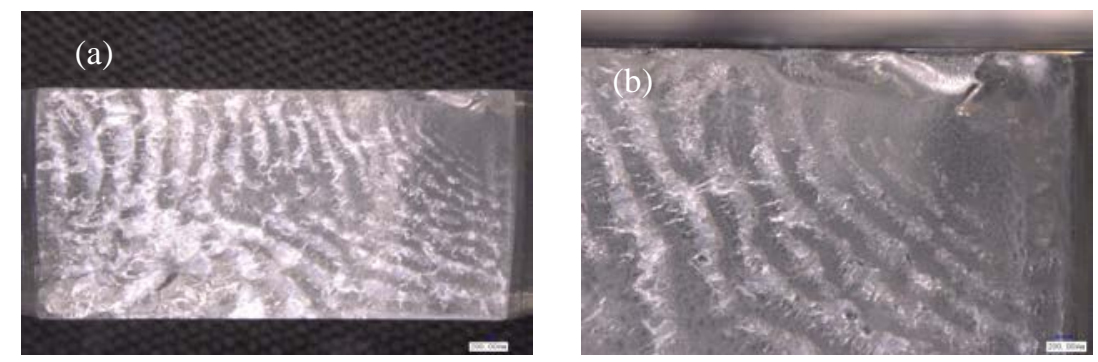

Fig.4 Tensile morphology experiencing 720 hours heat aging test (a)fracture picture, (b)source area morphology, (c)morphology near Source area, (d)morphology far away from source area
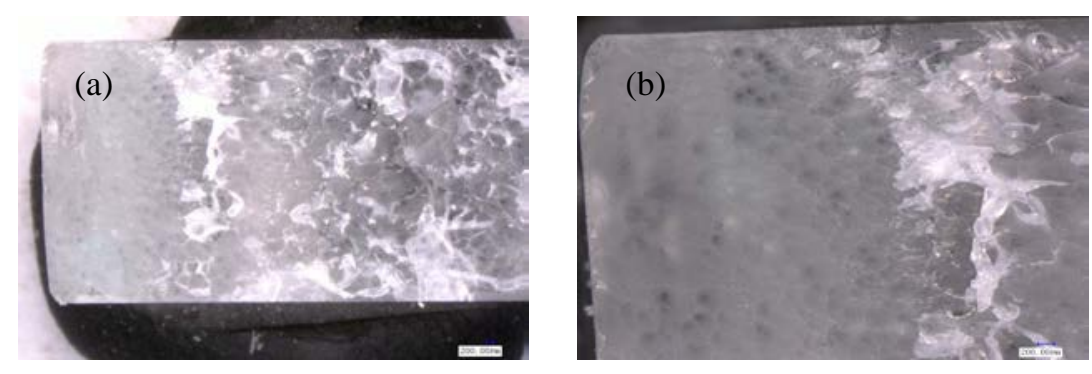

Fig.5 Tensile morphology experiencing 720 hours salt fog test, (a)fracture picture, (b)source area morphology

\section{Stress-Solvent (95\% Enthyl alcohol) Silver Grain Test Results}

\section{Stress-Solvent Silver Grain}

According to HB/T6657 (Aviation organic glass silver grain test method), test the sample's stress-solvent silver grain properties after they have been experienced different time accelerated 
aging test, including damp heat test, heat aging test, salt fog test, evaluate the threshold stress when the sample surface produce silver grain under the bending stress and solvent ( $95 \%$ enthyl alcohol), loading speed is $0.4 \mathrm{~mm} / \mathrm{min}$, the results are shown in Table 3 .

Table 3 Stress-solvent (95\% enthyl alcohol) silver grain Test results

\begin{tabular}{llllclll}
\hline $\begin{array}{l}\text { Test } \\
\text { stage }\end{array}$ & time & $\mathrm{b} /(\mathrm{mm})$ & $\mathrm{h} /(\mathrm{mm})$ & $\mathrm{a} /(\mathrm{mm})$ & $\mathrm{P} /(\mathrm{N})$ & $\mathrm{Y} /(\mathrm{MPa})$ & Retention rate/(\%) \\
\hline $\begin{array}{l}\text { Initial } \\
\text { sample }\end{array}$ & $0 \mathrm{~h}$ & 19.8 & 8.1 & 55 & 252 & 32.0 & - \\
\hline \multirow{2}{*}{ Damp } & $120 \mathrm{~h}$ & 20.6 & 8.2 & 55 & 206.9 & 24.7 & 77.2 \\
heat test & $360 \mathrm{~h}$ & 20.6 & 8.1 & 55 & 158.6 & 19.4 & 60.6 \\
& $720 \mathrm{~h}$ & 20.6 & 8.1 & 55 & 154.0 & 18.8 & 58.8 \\
\hline \multirow{2}{*}{ Heat } & $120 \mathrm{~h}$ & 20.0 & 8.1 & 55 & 199.5 & 25.1 & 78.4 \\
aging & $360 \mathrm{~h}$ & 20.0 & 8.1 & 55 & 174.8 & 22.0 & 68.8 \\
test & $720 \mathrm{~h}$ & 20.0 & 8.1 & 55 & 165.4 & 20.8 & 65.0 \\
\hline \multirow{2}{*}{ Salt fog } & $120 \mathrm{~h}$ & 19.9 & 8.1 & 55 & 174.2 & 22.0 & 68.8 \\
test & $360 \mathrm{~h}$ & 20.1 & 8.2 & 55 & 144.2 & 17.6 & 55.0 \\
& $720 \mathrm{~h}$ & 20.0 & 8.2 & 55 & 137.7 & 16.9 & 52.8 \\
\hline
\end{tabular}

From Table 3, we can see, after experiencing 120 hours damp heat test, 120 hours heat aging test, 120 hours salt fog test, the sample stress-solvent silver grain(95\% enthyl alcohol) are respectively 24.7MPa, 25.1MPa, 22.0MPa, after experiencing 360 hours accelerated aging test, they are respectively $19.4 \mathrm{MPa}, 22.0 \mathrm{MPa}, 17.6 \mathrm{MP}$, after experiencing 720 hours accelerated aging test, they are respectively $18.8 \mathrm{MPa}, 20.8 \mathrm{MPa}, 16.9 \mathrm{MPa}$. Although the retention rate are comparatively higher, when the sample experience $720 \mathrm{~h}$ accelerated aging test, stress-solvent silver grain are no less than $16.9 \mathrm{MPa}$ which is this type material' s indicator, so this type casting organic glass have the potential to continue to use a certain calendar time.

\section{Stress-Solvent Silver Grain Morphology}

Fig 6 is the sample stress-solvent silver grain morphology of initial YB-3 sample being used to the specified life, of that experiencing 720 hours damp heat test, of that experiencing 720 hours heat aging test and of that experiencing 720 hours salt fog test.
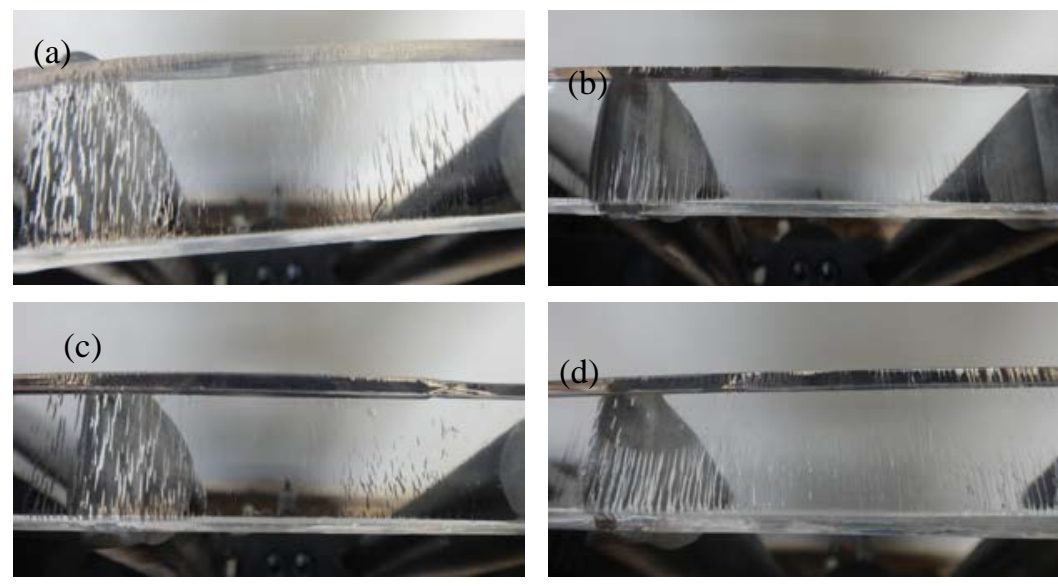

Fig.6 Silver grain morphology (a) before accelerated aging test (b) experiencing 720 hours damp heat test (c) experiencing 720 hours heat aging test (d) experiencing 720 hours salt fog test

From fig6, we can see that the 4 kinds dfferent sample stress-solvent silver grain morphologies have the similar characteristics, they are comparatively long and deep, take on linetype, the reason is that the long molecular chains are out-of order during the forming, under the bending stress 
and $95 \%$ enthyl alcohol, the extension of the silver grain is easy, the silver grain gradually spread, so they take on linetype character.

\section{Impact Test Results}

\section{Impact Strength}

According to GB/T1043 (Plastics-Determination of charpy impact strength of rigid materials), test sample's impact properties after they have been experienced different time accelerated aging test, salt fog test, the pendulum is $1 \mathrm{~J}$, the span is $40 \mathrm{~mm}$, the results are shown in Table 4.

Table 4 Results of Impact Strength

\begin{tabular}{lccccccc}
\hline Test stage & time & $\mathrm{b} /(\mathrm{mm})$ & $\mathrm{d} /(\mathrm{mm})$ & $\mathrm{a}(\mathrm{KJ} / \mathrm{m} 2)$ & $\mathrm{A} /(\mathrm{J})$ & $\begin{array}{l}\text { Strength } \\
\text { rate/(\%) }\end{array}$ & retention \\
\hline Initial sample & $0 \mathrm{~h}$ & 6.4 & 4.0 & 12.0 & 0.307 & 92.5 \\
\hline \multirow{3}{*}{ Damp heat test } & $120 \mathrm{~h}$ & 6.4 & 4.1 & 11.1 & 0.290 & 92.5 \\
& $360 \mathrm{~h}$ & 6.4 & 4.0 & 10.9 & 0.278 & 90.1 \\
& $720 \mathrm{~h}$ & 6.4 & 4.1 & 10.4 & 0.273 & 86.7 & \\
\hline \multirow{3}{*}{ Heat aging test } & $120 \mathrm{~h}$ & 6.0 & 4.0 & 11.7 & 0.280 & 97.5 \\
& $360 \mathrm{~h}$ & 6.2 & 4.0 & 10.1 & 0.250 & 84.2 \\
& $720 \mathrm{~h}$ & 6.2 & 3.8 & 9.08 & 0.214 & 75.7 \\
Salt fog test & $120 \mathrm{~h}$ & 6.4 & 4.0 & 11.1 & 0.284 & 92.5 \\
& $360 \mathrm{~h}$ & 6.4 & 4.1 & 10.5 & 0.275 & 87.5 \\
& $720 \mathrm{~h}$ & 6.2 & 4.1 & 10.4 & 0.264 & 86.7 & \\
\hline
\end{tabular}

From Table 4, we can see, after experiencing 120 hours damp heat test, 120 hours heat aging test, 120 hours salt fog test, the sample impact strength are respectively 11.1MPa, $11.7 \mathrm{MPa}, 11.1 \mathrm{MPa}$, compared with that of the initial sample, strength retention rate are higher 92 percent, after experiencing 360 hours accelerated aging test, they are respectively $10.9 \mathrm{MPa}, 10.1 \mathrm{MPa}, 10.5 \mathrm{MPa}$ and the strength retention rate are higher 84 percent, after experiencing 720 hours accelerated aging test, they are respectively $10.4 \mathrm{MPa}, 9.1 \mathrm{MPa}, 10.4 \mathrm{MPa}$ and the strength retention rate are higher 75 percent. The results show when the samples which have been used to the specified life experience 360 hours heat aging test, 360 hours heat aging test, 360 hours salt fog test, the bending strength only slightly decline, so this type casting organic glass have the potential to continue to use a certain calendar time.

\section{Impact Fracture Morphology}

Figs 7-10 are respectively the sample's impact fracture morphology of initial YB-3 sample being used to the specified life, of that experiencing 720 hours damp heat test, of that experiencing 720 hours heat aging test and of that experiencing 720 hours salt fog test. From Figs 7-10 we can see that the 4 kinds different sample tensile fracture morphologies have the similar characteristics, the hole fracture can divide 3 areas: source area, near source area, far away from source area. The whole fracture surfaces are very smooth, present fast fracture characteristics, the extension direction parallel to the impact load. Compared with that of initial sample, the extension area of the 3 accelerated aging test specimens' fracture take on a certain toughness characteristics on the sample fracture. 

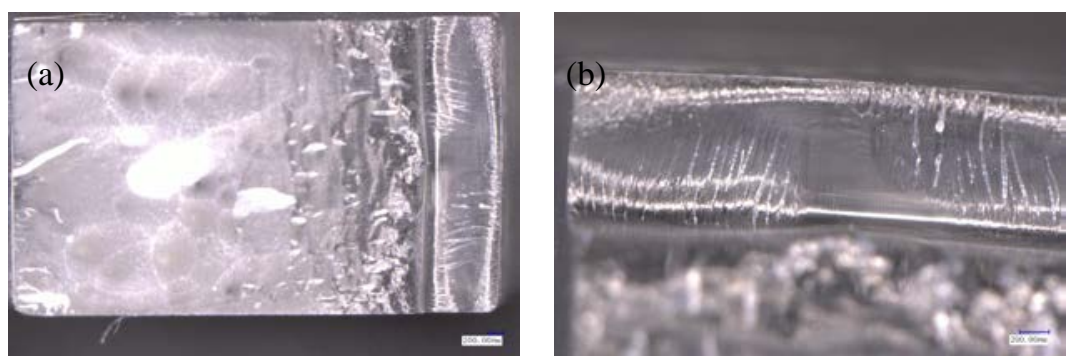

Fig.7 Impact Fracture Morphology before Accelerated aging test (a)Fracture picture, (b)Source area morphology
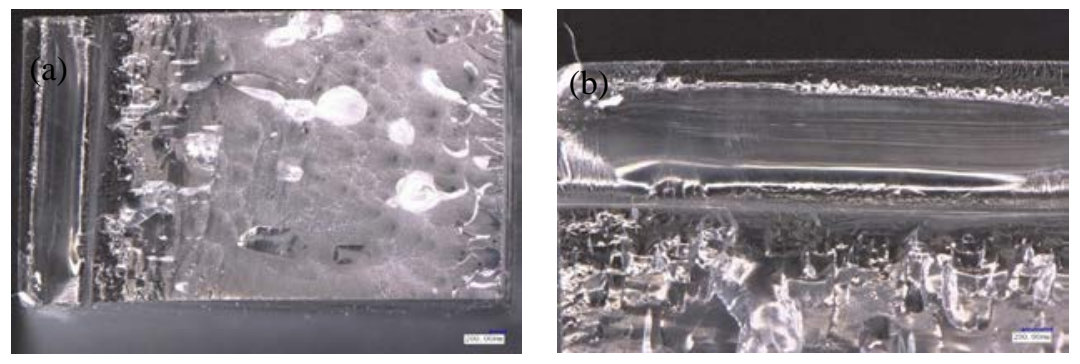

Fig.8 Tensile morphology experiencing 720 hours damp heat test (a)Fracture picture, (b)Source area morphology
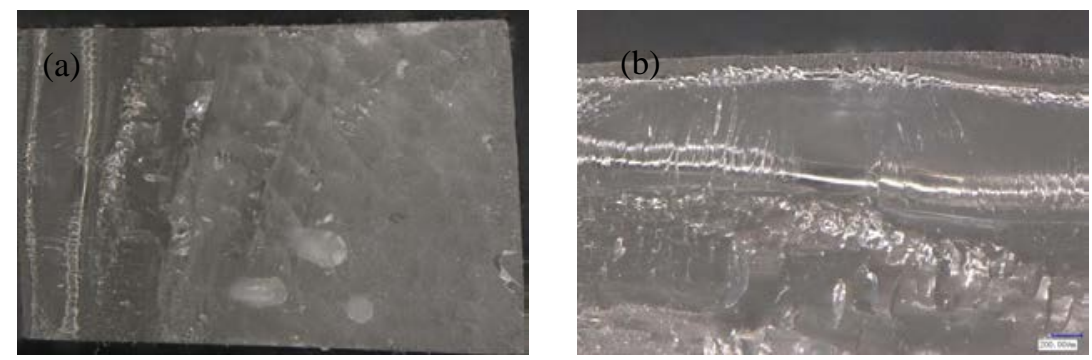

Fig.9 Tensile morphology experiencing 720 hours heat aging test (a)Fracture picture, (b)Source area morphology
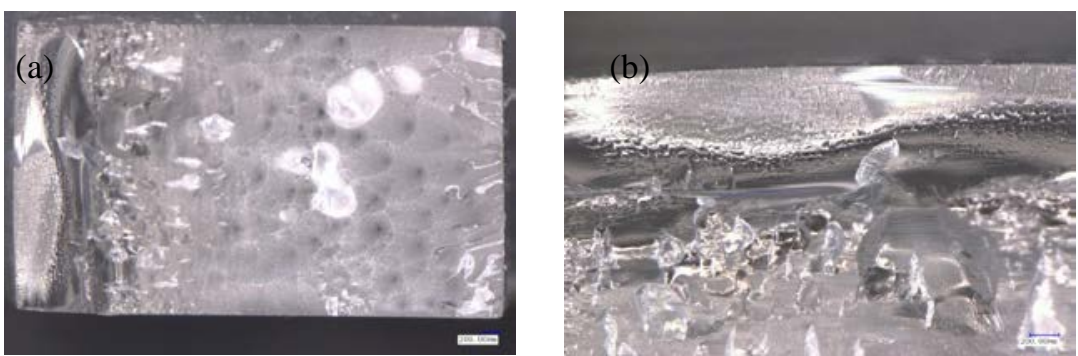

Fig.10 Tensile morphology experiencing 720 hours salt fog test (a)Fracture picture, (b)Source area morphology

\section{Conclusion}

The results of accelerated aging test show that the pouring organic glass whose brand is YB-3, which is now one of the widely used to manufacture the aircraft cockpit transparent parts aircraft cockpit transparent parts and have been used to the specified life, compared with the initial sample, the 
properties of the samples, such as bending strength, tensile strength, stress-solvent silver grain when they have experienced 720 hours damp heat test, 720 hours heat aging test, 720 hours salt fog test, only slightly decline, have the potential to continue to use a certain calendar time.

\section{Reference}

[1] Beijing Institute of aeronautical materials. Summary to the aviation organic glass ten years atmospheric aging performance research. 1992

[2] Beijing Institute of aeronautical materials. Mechanical properties of aviation organic glass under different temperatures. 1986

[3] Shanghai Shanhu chemical factory. YB-3 aviation organic glass performance data and statistics. 1985

[4] GU Gaoming. Handbook of engineering materials (2nd Edition) vol. 7[M]. Beijing: China standards press, 2002

[5] YAN Yue, LI Lei. New progress on the application study of transparent material for aviation cockpit[M]. Beijing: National defence industry press, 2011 